\title{
Patched homolog 1 gene mutation (p.G1093R) induces nevoid basal cell carcinoma syndrome and non-syndromic keratocystic odontogenic tumors: A case report
}

\author{
GIOVANNI PONTI ${ }^{1,6}$, ANNAMARIA POLLIO ${ }^{2}$, LORENZA PASTORINO $^{3}$, \\ GIOVANNI PELLACANI ${ }^{1}$, CRISTINA MAGNONI ${ }^{1}$, SABINA NASTI ${ }^{3}$, GIULIO FORTUNA ${ }^{2,4}$, \\ ALDO TOMASI $^{6}$, GIOVANNA BIANCHI SCARRA ${ }^{3,5}$ and STEFANIA SEIDENARI ${ }^{1}$
}

\footnotetext{
${ }^{1}$ Department of Head and Neck Surgery, Division of Dermatology, University of Modena and Reggio Emilia, Modena;

${ }^{2}$ Department of Odontostomatological and Maxillofacial Sciences, Oral Medicine Unit, School of Medicine and Surgery, Federico II University of Naples, Naples; ${ }^{3}$ Molecular Genetics Unit, University-Hospital of Genoa, Genoa, Italy;

${ }^{4}$ Department of Dermatology, Stanford University School of Medicine, Center for Clinical Sciences Research, Stanford, USA; ${ }^{5}$ Laboratory of Rare Hereditary Cancers, San Martino Hospital, Genoa; ${ }^{6}$ Department of Laboratory, Pathological Anatomy and Forensic Medicine, University of Modena and Reggio Emilia, Modena, Italy
}

Received February 2, 2012; Accepted March 28, 2012

DOI: $10.3892 / \mathrm{ol} .2012 .707$

\begin{abstract}
Mutations in the Patched homolog 1 (PTCH1) gene lead to an autosomal dominant disorder known as nevoid basal cell carcinoma syndrome (NBCCS) or Gorlin syndrome (GS). Several PTCH1 mutations have been observed in NBCCS associated with keratocystic odontogenic tumors (KCOTs), including non-syndromic KCOTs. The missense mutation c.3277G >C (p.G1093R) in exon 19 of the PTCH1 gene has only been reported in non-syndromic KCOTs. The present study reports for the first time a familial case (father and daughter) of NBCCS and KCOTs, carrying the same c.3277G $>C$ (p.G1093R) germline mutation. This observation suggests that this missense mutation is involved in the pathogenesis of NBCCS as well as in a subset of non-syndromic KCOTs. The identification of a missense mutation may lead to an earlier diagnosis of NBCCS.
\end{abstract}

\section{Introduction}

Nevoid basal cell carcinoma syndrome (NBCCS; also known as Gorlin syndrome; OMIM no. 109400) is a rare autosomal dominant disorder. The disease is characterized by multiple basal cell carcinomas, keratocystic odontogenic tumors (KCOTs) of the jaw, palmar and/or plantar pits and developmental defects and skeletal anomalies, including bifid, fused

Correspondence to: Dr Giovanni Ponti, Department of Head and Neck Surgery, Division of Dermatology, University of Modena and Reggio Emilia, via del Pozzo, 71, I-41100 Modena, Italy

E-mail: giovanni.ponti@unimore.it

Key words: nevoid basal cell carcinoma syndrome, PTCH1, odontogenic keratocysts, Gorlin syndrome and splayed ribs, intracranial calcification, for example of the falx cerebri, and a variety of other benign or malignant tumors, including ovarian fibroma, medulloblastoma, rhabdomyosarcomas and cardiac fibromas (1).

The incidence of NBCCS varies greatly among countries from one case per 55,600 (2) to one case per 256,000 in the population (3). The prevalence is predicted to be markedly higher in individuals younger than 20 years who present with basal cell carcinomas (BCCs) (4).

Since the discovery in 1996 that NBCCS might be associated with germline mutations in the PTCH1 gene $(5,6)$ approximately 280 germline mutations have been identified worldwide (7).

The PTCH1, or human homolog 1 of the Drosophila Patched gene, mapped on chromosome 9q22.3, consists of 23 exons and encodes an integral membrane protein of 1,447 amino acids, Patched 1 (PTCH1) with 12 transmembrane regions, 2 extracellular loops and a putative sterol-sensing domain (8). PTCH mutations are involved in the formation of syndromic as well as non-syndromic keratocysts (9). Non-syndromic KCOTs are common benign cystic tumors of the jaw (10).

The vast majority of cysts occur sporadically and in a single form on the upper and/or lower jaw of middle-aged individuals. When associated with NBCCS, these lesions appear earlier, often during the first or second decade of life, and may be multiple (10). Loss of heterozygosity on chromosome 9q22.3 has been described in patients with sporadic and syndrome-associated odontogenic keratocysts $(11,12)$. In addition, somatic mutations in the PTCH1 gene in odontogenic keratocysts associated with NBCCS have previously been described (13).

Recently, a novel missense germline mutation c. $3277 \mathrm{G}>\mathrm{C}$ (p.G1093R) in exon 19 of the PTCH1 gene has been described as being responsible for non-syndromic KCOTs in a Chinese 
family without evidence of NBCCS, suggesting a genotypephenotype correlation (14).

The present study reports for the first time this same mutation (p.G1093R) in a familial case of NBCCS and KCOTs, in which father and daughter presented with numerous basal cell carcinomas and multiple KCOTs of the jaw. Unlike the previous study (14), this case report widens the phenotypic spectrum of this missense mutation.

\section{Patients and methods}

Case report. A 36-year-old woman was referred to the Department of Dermatological and Genetic Counseling due to multiple BCCs and KCOTs of the jaw, diagnosed at the age of 25 and 14 years, respectively. The patient presented with low height, weight and occipitofrontal circumference (OFC $<97$ th percentile) within normal limits, extremely light pigmentation of the skin and multiple palmoplantar pits on the hands and feet. The patient also presented with multiple papular and nodular lesions located on the face and trunk.

On physical examination, round or oval-shaped lesions 3-10 $\mathrm{mm}$ in diameter with a smooth or ulcerated and crusted surface were observed on the face and trunk (Fig. 1). Surgical excision of numerous lesions was performed. Histopathological examination revealed the presence of nests of basaloid cells, arranged at the periphery of the nodules in palisading structures. A diagnosis of multiple BCCs was made.

The patient had undergone surgical excision of multiple BCCs $(>20)$ on the face and trunk over a period of 21 years of dermatological follow-up. At the age of 15, the patient also underwent surgical enucleation of osteolytic lesions located in her jaw and a histopathological diagnosis of keratocysts was made. Cardiac and gynecological ultrasound evaluations did not reveal any abnormalities, and neither did radiographical examinations of the vertebral column and thoracic cage. Therefore, in line with the major and minor criteria currently present in the literature (15), a diagnosis of NBCCS was made, as four major criteria were fulfilled, including the presence of a first-degree relative affected by NBCCS. The patient had been born at term from non-consanguineous parents and had two unaffected siblings. However, the proband reported that her 52-year-old father had previously undergone surgical excision of multiple cutaneous lesions, which had been histologically diagnosed as BCCs. No documented evidence of KCOT was available for this patient although the proband referred to several non-specific dental problems. No BCCs developed among other family members.

Cytogenetic and molecular analysis. Peripheral blood samples were collected from the proband and her father. Informed consent was obtained from the two patients. Molecular analysis of PTCH1 was performed as previously described (3). The PTCH1 cDNA sequence from GenBank (Accession number U59464.1) was used as a reference sequence, where the A of the ATG translation initiation start site represents nucleotide +1 .

Sequencing analysis of the constitutional DNA of the proband and her father led to the identification of the same exon 19 missense mutation of PTCH1 (p.G1093R). The CGA>GGA (p.G1093R) switch in the PTCH1 gene introduces the substitution of a highly conserved glycine residue located in the 10th transmembrane region of the PTCH protein. This region was previously described in familiar KCOT patients (14) showing heterozygosity at nucleotide c.3277, which differs from the proband in being a $\mathrm{G}>\mathrm{A}$ transversion and not a $\mathrm{G}>\mathrm{C}$ transition, although in both cases, the result was a $\mathrm{G}$ to $\mathrm{R}$ substitution at amino acid position 1093. The web-based software applications PolyPhen, SIFT and PMUT were used to predict the potential functional and structural effects of the G1093R missense variant. All predictions revealed that this variant is pathogenetic.

\section{Discussion}

The identification of a germline missense mutation c.3277G $>C$ (p.G1093R) in the PTCH1 sequence of a NBCCS patient suggests a new hypothesis in the genetic disease process. A complete clinical examination supported by histological and radiological findings in the presence of related patients confirmed the diagnosis of NBCCS. Therefore, this family may be considered affected by NBCCS with autosomal dominant inheritance. The missense germline mutation c.3277G $>C$ (p.G1093R) in the PTCH1 gene, located at chromosome $9 q 22.3$, has only been associated with non-syndromic KCOTs (14) and sporadic NBCCS (16).

This particular mutation has previously been reported in five patients from a Chinese family presenting with only signs of KCOTs and no other major or minor criteria of NBCCS. In this study, the mutation c.3277G>C (p.G1093R) was considered to be causative and indicative of non-syndromic KCOTs as it was identical in all patients in the same family following DNA sequence analysis of all 23 exons of the PTCH1 gene (14). The same germline mutation of the PTCH1 gene has previously only been reported in a French patient with sporadic NBCCS (16).

Normally, the PTCH1 gene codes for a protein that is a 12-pass-transmembrane receptor for Sonic Hedgehog and other Hedgehog proteins for repressing the functions of the signaling effector Smoothened, a member of the seven-transmembrane receptor superfamily. The Hedgehog $(\mathrm{HH})$ signaling pathway is pivotal in patterning, morphogenesis and growth in numerous tissues, including teeth (17-19). It is also known that $\mathrm{HH}$ signaling regulates the proliferation of distinct cell types via the direct activation of genes that are involved in cell cycle progression (20). Therefore, it is plausible that the increased proliferative activity observed in KCOTs, compared with other odontogenic cysts, is associated with an uncontrolled $\mathrm{HH}$ activity pathway (7).

Notably, this study reports an isolated missense mutation c.3277G >C (p.G1093R) of a single amino acid located in the 10th transmembrane region of the $\mathrm{PTCH}$ protein that causes one highly conserved glycine residue transit to arginine on the 10th transmembrane region of the PTCH protein. This glycine residue is highly conserved among humans, mice, rats, chicks and zebrafish, suggesting that it is functionally significant (14).

In line with previous studies, no correlation between the position of the germline mutation and the observed phenotype in NBCCS patients was detected $(8,21)$ and no genotype-phenotype correlation was found in the patients. The 


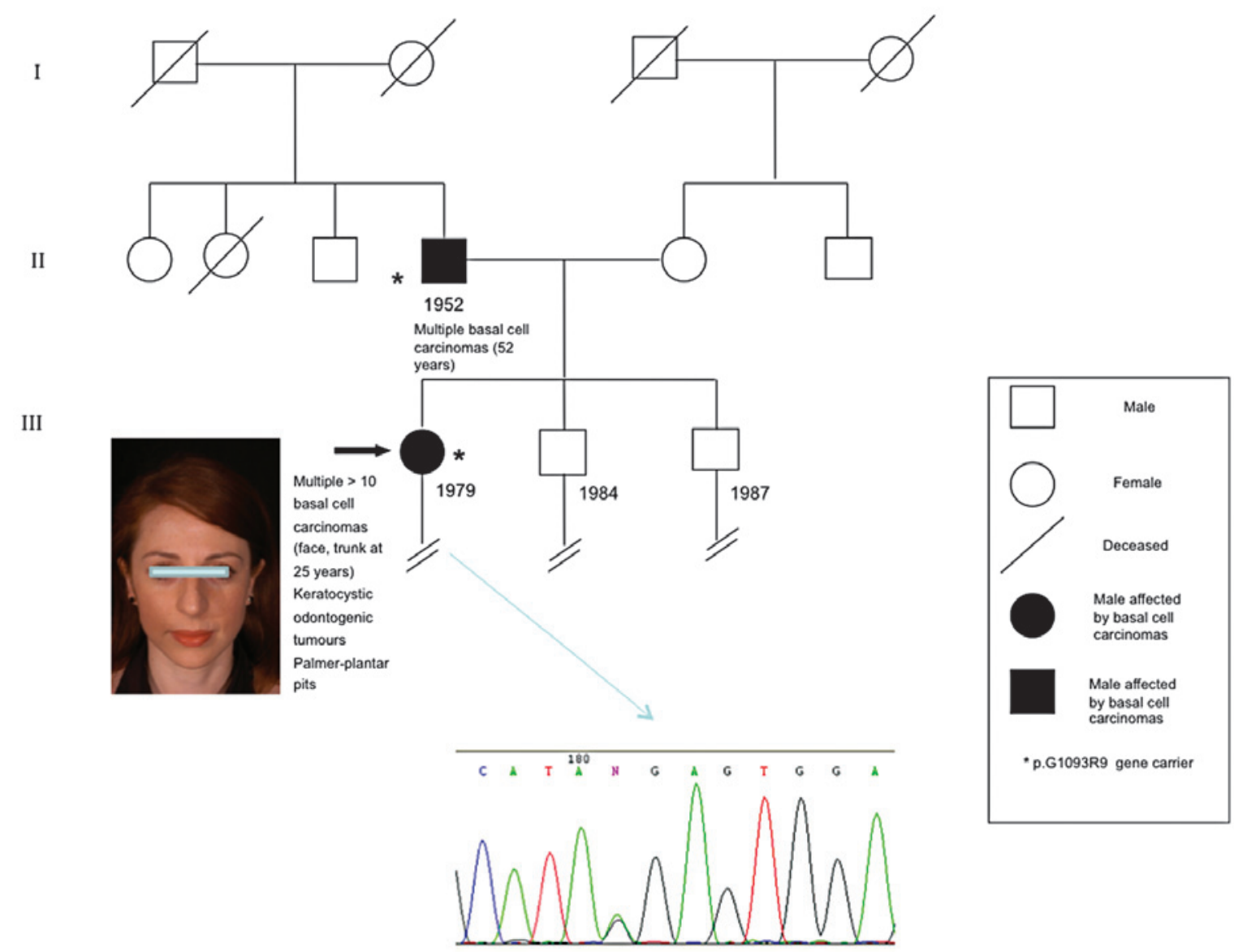

Figure 1. Family pedigree of the proband (black arrow) cosegregating PTCH1 exon 19 germline mutation (p.G1093R) and clinical features of NBCCS in the proband. PTCH1, Patched 1; NBCCS, nevoid basal cell carcinoma syndrome.

lack of a genotype-phenotype correlation is known for other genes involved in familial cancer (neurofibromatosis type 1 , Muir-Torre syndrome) for which identical mutations did not cause similar clinical features in related and unrelated patients $(22,23)$. This suggests that additional factors are involved in the development of clinical symptoms in NBCCS.

It would be useful to observe whether this amino acid is necessary for the interaction of Hedgehog with its PTCH receptor. However, no mutagenesis data or binding studies are available to document the effects of this mutation.

At present, no founder effect of PTCH1 gene mutation has been described in the literature and the present study results did not have any reason to support a founder effect. Certain mutations in different exons have been reported twice in the literature without knowledge of recurrence $(5,8,21)$. As yet, no conclusive evidence for a genotype-phenotype correlation in Gorlin syndrome has been demonstrated and there is adequate variation in single families to suggest that environmental exposure and modifier genes justify much of the variation.

The considerable inter- and intra-familial variability in a number of genetic diseases is likely to result from the action of modifier genes. Increasing evidence now suggests that the manifestations of a number of genetic disorders are influenced by modifying genes distinct from the disease locus. Specific modifying loci have also been identified. For example, two or more modifiers of the phenotype of the Multiple intestinal neoplasia (Min) mouse model of familial adenomatous polyposis (FAP) are known to exist (24). The type and position of a mutation have been shown to affect phenotype for a number of tumor-prone disorders, including neurofibromatosis type 2 (NF2) $(25,26)$ and FAP (27).

This phenotypic diversity strongly suggests that the final phenotypic outcome is modified by epigenetic factors, including ethnicity and environmental factors. Among these, ultraviolet (UV) light is one of the most high-risk factors for BCC development in NBCCS (28). The increased frequency of BCCs in Caucasian (80\%) compared with African-American individuals $(38 \%)$ has been reported in other studies $(29,30)$ and the lower frequency of BCCs in the African-American group may be associated with increased protection from UV light due to skin pigmentation (31).

To the best of our knowledge, this is the first study reporting a correlation between the missense mutation c.3277G >C (p.G1093R) and NBCCS-associated phenotype with the presence of multiple KCOTs, suggesting that a missense mutation induces different clinical phenotypes. The identification of a new mutation in NBCCS may facilitate diagnostic testing for families and for carrier parents, siblings and other family members. An accurate and close surveillance for dermatological and oropharyngeal lesions as well as for the risk of malignancy development is mandatory in these individuals. 


\section{References}

1. Gorlin RJ: Nevoid basal cell carcinoma syndrome. Dermatol Clin 13: 113-125, 1995.

2. Evans DG, Ladusans EJ, Rimmer S, Burnell LD, Thakker N and Farndon PA: Complications of the naevoid basal cell carcinoma syndrome: results of a population based study. J Med Genet: 30 460-464, 1993.

3. Pastorino L, Cusano R, Nasti S, et al: Molecular characterization of Italian nevoid basal cell carcinoma syndrome patients. Hum Mutat 25: 322-323, 2005 .

4. Stone DM, Hynes M, Armanini M, et al: The tumour-suppressor gene patched encodes a candidate receptor for Sonic hedgehog. Nature 384: 129-134, 1996.

5. Hahn H, Christiansen J, Wicking C, Zaphiropoulos PG, Chidambaram A, Gerrard B et al: A mammalian patched homolog is expressed in target tissues of sonic hedgehog and maps to a region associated with developmental abnormalities. J Biol Chem 271: 12125-12128, 1996.

6. Johnson RL, Rothman AL, Xie J, et al: Human homolog of patched, a candidate gene for the basal cell nevus syndrome. Science 272: 1668-1671, 1996

7. Diniz MG, Borges ER, Guimarães ALS, et al: PTCH1 isoforms in odontogenic keratocysts. Oral Oncol 45: 291-295, 2009.

8. Wicking C, Shanley S, Smyth I, et al: Most germ-line mutations in the nevoid basal cell carcinoma syndrome lead to a premature termination of the PATCHED protein, and no genotype-phenotype correlations are evident. Am J Hum Genet 60: 21-26, 1997.

9. Barreto DC, Gomez RS, Bale AE, Boson WL and De Marco L: PTCH gene mutations in odontogenic keratocysts. J Dent Res 79: $1418-1422,2000$

10. Woolgar JA, Rippin JW and Browne RM: The odontogenic keratocyst and its occurrence in the nevoid basal cell carcinoma syndrome. Oral Surg Oral Med Oral Pathol 64: 727-730, 1987.

11. Lench NJ, High AS, Markham AF, Hume WJ and Robinson PA Investigation of chromosome 9q22.3-q31 DNA marker loss in odontogenic keratocysts. Eur J Cancer B Oral Oncol 32: 202-206, 1996.

12. Levanat S, Gorlin RJ, Fallet S, Johnson DR, Fantasia JE and Bale AE: A two-hit model for developmental defects in Gorlin syndrome. Nat Genet 12: 85-87, 1996.

13. Lench NJ, Telford EA, High AS, Markham AF, Wicking C and Wainwright BJ: Characterization of human patched germ line mutations in naevoid basal cell carcinoma syndrome. Hum Genet 100: 497-502, 1997

14. Wang X, Lu Y, Shen G and Chen W: One germline mutation of PTCH gene in a Chinese family with non-syndromic keratocystic odontogenic tumours. Int J Oral Maxillofac Surg 40: 829-833, 2011

15. Kimonis VE, Goldstein AM, Pastakia B, et al: Clinical manifestations in 105 persons with nevoid basal cell carcinoma syndrome. Am J Med Genet 69: 299-308, 1997.
16. Pruvost-Balland C, Gorry P, Boutet N, et al: Clinical and genetic study in 22 patients with basal cell nevus syndrome. Ann Dermatol Venereol 133: 117-123, 2006.

17. Dassule HR, Lewis P, Bei M, Maas R and McMahon AP: Sonic hedgehog regulates growth and morphogenesis of the tooth. Development 127: 4775-4785, 2000.

18. Oro AE and Higgins K: Hair cycle regulation of Hedgehog signal reception. Dev Biol 255: 238-248, 2003.

19. Hebrok M, Kim SK, St Jacques B, McMahon AP and Melton DA Regulation of pancreas development by hedgehog signaling. Development 127: 4905-4913, 2000.

20. Duman-Scheel M, Weng L, Xin S and Du W: Hedgehog regulates cell growth and proliferation by inducing Cyclin D and Cyclin E. Nature 417: 299-304, 2002

21. Boutet N, Bignon YJ, Drouin-Garraud V, et al: Spectrum of PTCH1 mutations in French patients with Gorlin syndrome. J Invest Dermatol 121: 478-481, 2003.

22. Ponti G, Losi L, Martorana D, et al: Clinicopathological and biomolecular findings in Italian patients with multiple cutaneous neurofibromas. Hered Cancer Clin Pract 9: 6, 2011.

23. Ponti G, Losi L, Pedroni M, et al: Value of MLH1 and MSH2 mutations in the appearance of Muir-Torre syndrome phenotype in HNPCC patients presenting sebaceous gland tumors or keratoacanthomas. J Invest Dermatol 126: 2302-2307, 2006.

24. Houlston RS and Tomlinson IP: Modifier genes in humans: strategies for identification. Eur J Hum Genet 6: 80-88, 1998.

25. Evans DGR, Trueman L, Wallace A, Collins S and Strachan T: Genotype/phenotype correlations in type 2 neurofibromatosis (NF2): evidence for more severe disease associated with truncating mutations. J Med Genet 35: 450-455, 1998.

26. Baser ME, Friedman JM, Aeschliman D, et al: Predictors of the risk of mortality in neurofibromatosis 2 . Am J Hum Genet 71: 715-723, 2002

27. Davies DR, G. Armstrong JG, Thakker N, et al: Severe Gardner syndrome in families with mutations restricted to a specific region of the APC gene. Am J Hum Genet 57: 1151-1158, 1995.

28. Tanioka M, Takahashi K, Kawabata T, et al: Germline mutations of the PTCH gene in Japanese patients with nevoid basal cell carcinoma syndrome. Arch Dermatol Res 2005: 296: 303-308, 2005.

29. Anderson DE, Taylor WB, Falls HF and Davidson RT: The nevoid basal cell carcinoma syndrome. Am J Hum Genet 19: 12-22, 1967.

30. Goldstein AM, Bale SJ, Peck GL and Di Giovanna JJ: Sun exposure and basal cell carcinomas in the nevoid basal cell carcinoma syndrome. J Am Acad Dermatol 29: 34-41, 1993.

31. Goldstein AM, Pastakia B, Di Giovanna JJ, et al: Clinical findings in two African-American families with the nevoid basal cell carcinoma syndrome (NBCC). Am J Med Genet 50: 272-281, 1994. 